\title{
A Crítica de Amartya Sen à Concepção Rawlsiana de Justiça
}

\section{The Amartya Sen's Criticism to the Rawlsiane Conception of Justice}

Flávio Pansieri

Pontifícia Universidade Católica do Paraná, Curitiba - PR, Brasil

Resumo: $\mathrm{O}$ presente artigo tem como intuito abordar o tema da justiça na obra do filósofo John Rawls e do economista Amartya Sen. O objetivo é apresentar, em um primeiro momento, a noção de justiça de Amartya construída sob uma ótica prática, ou seja, vinculada a uma ótica prospectiva de resolução de problemas sociais. Em seguida, serão abordados os princípios de justiça de John Rawls e a crítica de Sen a essa concepção denominada por ele institucionalismo transcendental. $\mathrm{O}$ intuito é estabelecer um paralelo entre duas concepções distintas do justo, no afã de se contribuir com o debate contemporâneo acerca do tema.

Palavras-chave: Justiça. Uma Teoria da Justiça. Amartya Sen. John Rawls.
Abstract: The purpose of this text is to focus on justice subject by the philosophy of John Rawls and the economic vision of Amartya Sen. The objective is to present, initially, Amartya's through about justice structured in a practical view, i.e., linked to a prospective point of view about solutions to social problems. Then, will be addressed the principles of justice by John Rawls and the critique of Amartya Sen to this conception, nominated as transcendental institutionalism by him. The intention is compose a parallel between these two different conception of fare, in the rush to contribute with this contemporary debate.

Keywords: Justice. Development as Freedom. A Theory of Justice. Amartya Sen. John Rawls.

\section{Introdução: 0 aporte ético nas questões econômicas}

Constitui-se encargo da economia uma discussão que perpasse por temas éticos? A despeito da aparente incompatibilidade destas áreas, uma

Recebido em: 11/03/2016

Revisado em: 20/10/2016

Aprovado em: 29/10/2016 
vez que a economia atual envereda um caminho de autoafirmação cujo enfoque se encontra mais na matemática e menos nas discussões das ciências humanas, Amartya Sen busca reaproximar estes dois domínios. Em Sobre Ética e Economia, livro escrito em 1986, o economista indiano leciona que a origem da economia moderna Pós-Revolução Industrial ocorreu pela conjugação de duas vertentes opostas e complementares: uma voltada para a ética (a partir dos escritos de Aristóteles) e outra voltada para a engenharia.

Embora a economia tenha a ética em sua gênese, o modelo predominante que a formatou a partir da Revolução Industrial é aquele que conecta economia e aspectos logísticos e de eficiência ao invés de estatuir valores e objetivos a serem alcançados pelo bem comum. Nesta perspectiva, o foco que interessa a economia não são os fins, mas os meios, ou seja, a resolução dos problemas técnicos que permeiam as relações econômicas. Em suma, a preocupação estaria voltada para as condições de realização dos negócios, os mercados financeiros e tudo aquilo que se relaciona com aspectos econômicos estruturantes (SEN, 1999, p. 20-24). Na visão de Amartya Sen, ética e economia deixaram de dialogar entre si.

Oportuno afirmar ainda que embora se reconheça a importância do desenvolvimento da perspectiva econômica pautada na engenharia apresentando o exemplo da "teoria do equilíbrio geral", por exemplo, que equaciona todas as variáveis relevantes nas relações de mercado -, Sen admite que o descaso pela abordagem ética apartou a evolução econômica dos temas sociais. Em outras palavras, o desenvolvimento da economia ao longo do século XX não ocorreu de modo coeso entre os contextos individual e social, fortalecendo o tema da desigualdade. $\mathrm{O}$ autor cita $\mathrm{O}$ exemplo da fome individual e coletiva: a despeito da crescente disponibilidade de alimentos, ela ainda constitui uma lamentável realidade em muitos lugares no planeta. Como isso pode ser possível, já que a questão não envolve a escassez de alimentos? O desencadeamento de um discurso ético na economia tem como jaez exatamente revelar tais e permitir perspectivas para ações políticas.

Com efeito, o constitucionalismo democrático colocou em cheque a corriqueira perspectiva econômica preocupada com os "meios". Avançan- 
do para temas ligados à ética e à moral, tais questões tornam inadequado o instrumental da análise econômica tradicional - questões, como, o que é o desenvolvimento, ou qual o modo como a sociedade deve viver, ou se é possível e válido buscar o bem comum pela via do Estado, e ainda se há justiça na atual formatação dos mercados financeiros. Este movimento tende a extrair a economia de seu caráter eficiente, puramente produtivo e individualista, para lhe lançar em uma fórmula pública e política. Em outras palavras, subverter a tendência natural do capitalismo ${ }^{1}$.

A retomada das questões de cunho ético e moral na economia e o foco voltado para o desenvolvimento do bem-estar fizeram com que Amartya Sen trilhasse a discussão sobre a justiça. As ideias de justo e de injusto emergem de modo natural como consectários dos pontos de análise propostos por Amartya, ao lado das noções de liberdade, divisão de recursos econômicos do Estado, políticas públicas, capacidade dos cidadãos para agir em prol de seus interesses e da coletividade, entre outras temáticas. A questão da justiça é trabalhada, sobretudo, no livro A Idéia de Justiça. No fulcro dessa obra, subjaz o propósito de contrapor a teoria de Amartya Sen com o modelo construtivista procedimental de justiça desenvolvido por John Rawls na teoria da justiça como equidade, um dos principais pensadores morais do seu tempo e considerado um dos grandes responsáveis por retomar temas da moralidade na segunda metade do século XX.

Esse é o substrato fundamental deste artigo. Seu escopo visa abordar a noção de justiça para Amartya Sen. Como a maioria dos autores da segunda metade do século XX se pautam (em apoio ou não) na noção de

\footnotetext{
${ }^{1}$ Ao tratar da política de Keynes (aquela que estruturou o Welfare State), Avelãs Nunes lembra que a ideia nunca foi resolver o problema distributivo no seio do capitalismo, mas salvar o próprio capitalismo ao tentar, naquele momento, reduzir as crises pelo qual ele passa e também que produz por essência. Nesse sentido: “[...] daí que eles não tenham resolvido o problema do 'subdesenvolvimento'; não tenham impedido o alargamento do fosso entre 'países desenvolvidos' e 'países subdesenvolvidos’; não tenham acabado com as crises cíclicas do capitalismo; não tenham posto cobro à desigualdade na distribuição do rendimento, cujo agravamento leva a que se fale já da necessidade de incluir no elenco dos direitos fundamentais o direito a uma igualdade razoável; não tenham acabado, evidentemente, com o regime do salariato e com a relação de exploração que lhe é inerente." (NUNES, 2007, p. 590).
} 
justiça desenvolvida por John Rawls, apresentar-se-ão alguns elementos da noção de justiça para Amartya Sen para, em seguida, tratar de Rawls e as críticas atinentes à sua concepção de justiça. $\mathrm{O}$ fulcro deste paralelo entre os dois autores é demarcar o ideal igualitário de cada um, a partir da crítica de Sen: enquanto ele pensa em uma justiça focada em realizações, o jurista trabalhou os "arranjos", isto é, uma estrutura lógico-dedutiva de instituições que Amartya denominou de institucionalismo transcendental. Oportuno pontuar que a análise sobre John Rawls se pauta apenas em seu livro Uma Teoria da Justiça.

\section{A Justiça Focada em Realizações}

No prefácio de A Idéia de Justiça, Amartya Sen salienta que não pretende trabalhar com categorias teóricas que planifiquem o conceito de justiça em um arquétipo social idílico. Em outras palavras, ele não busca princípios estruturantes de uma sociedade em uma perspectiva teórica, ou seja, não pensará a justiça em uma matriz procedimentalista. Em contrapartida, a partir das categorias de justo e injusto, seu intento está em encontrar razões que justifiquem a distância existente entre estes conceitos sob uma visão prática e realista do mundo.

Neste sentido, ainda antecipando questões no prefácio, Sen esclarece que sua perspectiva vai um pouco além da "limitada" ideia do contrato social rawlsiano ao pretender comparações em favor da promoção da justiça, citando como exemplos o combate à opressão - à escravidão ou à sujeição feminina - ou a negligência médica sistemática - que ocorre tanto pela inexistência de condições mínimas para este fim como pela falta de um sistema de cobertura médica aos mais necessitados (SEN, 2011, p. 13-14). A análise realizada nesta obra, publicada em 2009, aloca-se ao objetivo maior de Amartya Sen, que é a busca por fundamentos sobre a ideia de bem-estar, noção que lhe rendeu o Prêmio Nobel de Economia no ano de 1998.

Oportuno questionar desde então: qual o propósito de se teorizar sobre a justiça? Primeiro por uma questão de disciplina racional, haja vista a compreensão ser um processo de registro de percepções e um tema tão 
complexo como o da justiça envolve uma análise ampla e pormenorizada e tais objetivos necessitam do dispêndio de muito tempo de observação e estudo de modo a limitar tanto quanto possível a parcialidade dos juízos críticos. Segundo, para saber que tipo de teoria deve ser arquitetada. A teoria de Amartya Sen ataca a realidade posta, não se prendendo a idealizar modelos. Em seus termos, “[...] o objetivo é esclarecer como podemos proceder para enfrentar as questões sobre a melhoria da justiça e a remoção da injustiça, em vez de oferecer soluções para questões sobre a natureza da justiça perfeita" (SEN, 2011, p. 11).

Segundo Sen (2011), há pelo menos três diferenças entre a abordagem que ele elegeu para as teorias da justiça que emergiram na filosofia moral e política durante o século XX. Para a consecução de sua análise, é necessário, em primeiro lugar, encontrar meios de julgar a diminuição da injustiça e promoção da justiça. Em segundo lugar, considera-se a existência de diversas teorias que tratam do tema da justiça, como o igualitarismo e o utilitarismo. Parte de sua crítica se deve a falta de clareza que pode emanar da pretensão em se estabelecer uma sociedade perfeitamente justa a partir da aplicação de uma teoria imparcial única. Em outros termos, é complexa a tentativa de teorias transcendentais elegerem um sistema que seja inflexível e busca uma solução justa e perfeita para a resolução dos inúmeros problemas sociais: digressões em torno de ideais de justiça não podem legitimar a omissão em se atacar diretamente as desigualdades sociais. A terceira diferença ressaltada por Amartya entre a sua teoria da justiça e as formuladas ao longo do século XX guarda relação com as instituições sociais. Para ele, muitas injustiças remediáveis estão conectadas a transgressões comportamentais - o modo como as pessoas vivem - e não necessariamente às instituições sociais ${ }^{2}$. Em suma, Sen pontua para a "[...] necessidade de uma compreensão da justiça que seja baseada na realização está relacionada ao argumento de que a justiça não pode ser indiferente às vidas que as pessoas podem viver de fato." (SEN, 2011, p. 48).

\footnotetext{
${ }^{2}$ É bastante claro que Sen está fazendo uma crítica à teoria da justiça de Rawls, que se concentra predominantemente em "como estabelecer instituições justas" e, por outro lado, atribuem um “[...] papel acessório e secundário aos traços comportamentais.” (SEN, 2011, p. 13).
} 
Feitas tais considerações, abre-se um flanco para o estudo da liberdade no pensamento de Amartya Sen. Desse modo, além de tudo aquilo que pode ser conquistado com o esforço pessoal, a questão da liberdade se constitui como um traço elementar na vida pessoal e social ao permitir que, livremente, uma pessoa tenha a capacidade de decidir que tipo de vida pretende seguir. A capacidade de oferecer razões de escolha é um aspecto básico da vida humana: as pessoas não têm a obrigação de buscar tão somente o seu próprio bem-estar, mas ir além e observar o mundo que existe à sua volta.

Se as realizações sociais forem mensuradas através das capacidades que as pessoas de fato detêm - e não sob a ótica da utilidade ou da sua busca por felicidade pessoal -, Amartya Sen admite duas consequências importantes. A primeira consequência é a de tornar as pessoas responsáveis pelas suas próprias atitudes. A segunda consequência é que "[...] as vidas humanas são então vistas sem exclusão" (SEN, 2000, p. 322), ou seja, a fruição das liberdades substantivas das pessoas é critério determinante para a análise do desenvolvimento social. Subjaz a estas duas consequências a noção de que sem um mínimo desenvolvimento das liberdades substantivas, é complexo tratar da questão da responsabilidade pela construção de uma sociedade, sejam quais forem os seus objetivos (SEN, 2000, p. 322)3. Ou seja: como responsabilizar indivíduos - por exemplo, por não realizarem boas escolhas eleitorais - cujo traço fundamental é a escassez de recursos (saúde, educação, trabalho)?

Nessa medida, Sen relativiza os ideais em torno de categorias perfeitas de justiça. Ele procura salientar que a realidade é muito mais complexa do que as elucubrações de gabinete são capazes de dar solução. Todavia, não pretende também constituir um Estado meramente assistencial, mas criar oportunidades de escolha e decisões substantivas aos indivíduos

\footnotetext{
${ }^{3} \mathrm{O}$ argumento do apoio social para expandir a liberdade das pessoas pode ser considerado um argumento em favor da responsabilidade individual, e não contra ela. O caminho entre liberdade e responsabilidade é de mão dupla. Sem a liberdade substantiva e a capacidade para realizar alguma coisa, a pessoa não pode ser responsável por não fazê-la. Mas ter efetivamente a liberdade e a capacidade para fazer alguma coisa impõe à pessoa o dever de refletir sobre fazê-la ou não, e isso envolve responsabilidade individual. Nesse sentido, a liberdade é necessária e suficiente para a responsabilidade.
} 
ao proporcionar condições mínimas de vida. Serviços como educação básica e saúde, mas também proporcionar a liberdade de expressão e imprensa são elementos propiciadores de oportunidades, proporcionando o desenvolvimento das capacidades dos cidadãos e fortalecendo as suas respectivas liberdades substanciais que eclodem na condição de agente de cada integrante da sociedade.

Desse modo, o pensador indiano se preocupa com os reais fatores de diminuição de desigualdade social que ensejarão no desenvolvimento social. Por essa razão, é qualificado como um pensador do igualitarismo de bem-estar.

\section{O Renascimento do Contratualismo no Século XX: a Teoria da Justiça em John Rawls}

Em Uma Teoria da Justiça, John Rawls desde o limiar do texto lembra a centralidade da justiça para as instituições sociais. Segundo ele, [...] a justiça é a virtude primeira das instituições sociais, assim como a verdade o é dos sistemas de pensamento (RAWLS, 2008, p. 03-04) ${ }^{4}$. A fundamentação de uma teoria da justiça no bojo da tradição democrática é o seu principal intento de modo a fornecer uma "alternativa sistemática razoável ao utilitarismo" (RAWLS, 2008, p. XXXVI). A abordagem de Rawls se desenvolve no tocante a fornecer parâmetros principiológicos

\footnotetext{
${ }^{4}$ Ainda segundo Rawls, “[...] por mais elegante e econômica que seja, deve-se rejeitar ou retificar a teoria que não seja verdadeira; da mesma maneira que as leis e as instituições, por mais eficientes e bem organizadas que sejam, devem ser reformuladas ou abolidas se forem injustas." (RAWLS, 2008, p. 4).

${ }^{5}$ Esta consideração foi feita no prefácio à segunda edição da obra escrita por Rawls no ano de 1990. Ele alega que a fragilidade "[...] da doutrina utilitarista para servir de base às instituições da democracia constitucional [...]" constitui o seu grande propósito para buscar uma alternativa às teses utilitárias. "Não acredito, acima de tudo [...]", assevera Rawls, "[...] que o utilitarismo consiga oferecer uma teoria satisfatória dos direitos e das liberdades fundamentais dos cidadãos como pessoas livres e iguais, requisito da mais alta importância para a teoria das instituições democráticas.” (RAWLS, 1990).
} 
na determinação dos direitos e deveres que constituem a base da própria cidadania democrática e condição sine qua non do Estado de Direito ${ }^{6}$.

A teoria da justiça de John Rawls é identificada como uma tentativa de encontrar um parâmetro moral básico da sociedade para que se possa, a partir de então, quando necessário, avaliar políticas fundamentais sob o prisma das instituições sociais de determinado país. Consoante a análise de Werle (2015, p. 263), a teoria rawlsiana é um padrão voltado para as instituições, em primeiro plano, e somente de modo secundário para os indivíduos à medida que "[...] estes vivem e levem adiante seus planos de vida sob as regras públicas estabelecidas por aquelas instituições". O próprio Rawls esclarece em seu texto que não pretende estabelecer uma teoria fundadora de uma sociedade hipotética, mas encontrar os princípios básicos sobre os quais a sociedade seria erigida e a concepção de justiça seria localizada. Em outras palavras, Rawls busca identificar um padrão pelo qual a sociedade pudesse se reconfigurar.

Em suas palavras:

Meu objetivo é apresentar uma concepção de justiça que generalize e eleve a um nível mais alto de abstração a conhecida teoria do contrato social conforme encontrada em, digamos, Locke, Rousseau e Kant. Para isso, não devemos achar que o contrato original tem a finalidade de inaugurar a determinada sociedade ou de estabelecer uma forma específica de governo. Pelo contrário, a idéia norteadora é que os princípios de justiça para a estrutura básica da sociedade constituem o objeto do acordo original. São eles os princípios que pessoas livres e racionais, interessadas em promover seus próprios interesses, aceitariam em uma situação de igualdade como definidores das condições fundamentais de sua associação. (RAWLS, 2008, p. 13-14)

A intenção que subjaz a teoria rawlsiana é estabelecer um modelo pelo qual as pessoas estabelecerão as suas vidas, o que em última análi-

\footnotetext{
${ }^{6}$ A este respeito, Denílson Luis Werle (2015, p. 263) comenta que “[...] a teoria da justiça de Rawls pretende fornecer um conjunto de princípios capaz de evitar a arbitrariedade moral na determinação dos direitos e deveres dos cidadãos e fornecer um ponto de vista comum a partir do qual reivindicações conflitantes dos cidadãos possam ser julgadas.
} 
se revela a tentativa de estabelecer algum parâmetro de controle para a complexidade do comportamento social. Por sua vez, seu objetivo é "[...] oferecer uma teoria razoável que contenha um conjunto básico de princípios com os quais possamos obter o consenso no debate sobre a justiça" (MORRISON, 2006, p. 469-470). A teoria de Rawls, portanto, reinaugura o arquétipo do contrato social ${ }^{7}$ exatamente por pensar em uma nova sociedade que seria fundada por determinados princípios de ação, identificando os princípios basilares da justiça para uma sociedade e identificar as suas instituições a tal base comparativa.

A partir dessa noção preliminar é importante destacar que John Rawls pretende aplicar a sua teoria a duas circunstâncias da justiça. Consoante expõe Werle (2015, p. 264), a primeira circunstância são questões de justiça distributiva decorrentes da escassez moderada dos recursos, no intuito de determinar as regras fundamentais da distribuição dos benefícios e encargos que são originados pela cooperação da sociedade. Uma vez que qualquer teoria de justiça precisa atacar o problema das profundas desigualdades sociais, Rawls não tem interesse em deixar esta importante questão no livre jogo dos mercados. A segunda circunstância se relaciona às questões de tolerância, ou seja, são necessários princípios de justiça para especificar direito e deveres dos cidadãos. Qualquer sociedade somente pode vicejar a partir da mínima coesão entre direitos e obrigações, embora em si reine a total disparidade de planos de vida, crenças, culturas, religiões e ideologias. Desse modo, é preciso oferecer algum padrão mínimo de organização a todos estes contrastes.

Para encarar esse desafio, Rawls se identifica com uma das principais ideias da moralidade para os autores liberais, que é a sobreposição da justiça em relação ao bem comum, concepção contrária, por exemplo,

\footnotetext{
${ }^{7}$ Rawls (2008, p. 19-20) aloca a sua teoria da justiça como equidade como "[...] um exemplo do que chamo de teoria contratualista". Ainda em suas palavras, "[...] o mérito da terminologia contratualista é expressar a idéia de que os princípios da justiça podem ser concebidos como princípios que seriam escolhidos por pessoas racionais e que, assim, é possível explicar e justificar as concepções de justiça”. Ainda acerca de sua opção pela idéia da teoria contratual, ele aduz que "[...] a palavra 'contrato' indica essa pluralidade, bem como a condição de que a divisão apropriada das vantagens esteja de acordo com princípios aceitáveis por todas as partes".
} 
a dos autores comunitaristas. Essa é a principal característica da teoria da justiça como equidade: a imposição de alguns critérios de justiça na moldagem da estrutura básica da sociedade (visão procedimental). Dessa forma, “[...] impõe-se certos limites iniciais ao que é bom e quais formas de caráter são moralmente dignas, e também aos tipos de pessoas que os seres humanos devem ser" (RAWLS, 2008, p. 38-39). O objetivo dessas limitações, comuns a todas as teorias da justiça, visa à satisfação dos princípios fundamentais nas circunstâncias vigentes. Werle (2015, p. 263-265) aduz para duas maneiras consectárias de compreensão à tese do justo preceder o bem como um reflexo do modus operandi argumentativo das teorias kantianas: a primeira maneira é a defesa normativa da inviolabilidade da pessoa, ou seja, a autonomia pessoal deve ser preservada em detrimento a todas as considerações coletivas de bem-estar, de bem comum ou qualquer outra finalidade enunciada sobre uma noção coletiva, que escapa à individualidade e a preferência dos indivíduos singularmente considerados já que cada um deles aquiesceu para a constituição do Estado. O objetivo desta noção de justiça é garantir as condições política, jurídicas e sociais - “[...] ao exercício da autonomia dos cidadãos considerados pessoas morais livres e iguais" (RAWLS, 2008, p. 4) ${ }^{8}$. O segundo modo concepção decorrente é o da neutralidade de justificação do Estado em face de concepções particulares do bem. Werle esclarece a necessidade de princípios fundamentais e comuns que sirvam como bastião em uma sociedade plural e heterogênea da qual emergem inúmeras concepções de vida. Assim, não há justificativa para a escolha de uma determinada concepção particular de bem que fundamente a sociedade, pois tal atitude frustraria a autonomia dos indivíduos, preceito elementar para qualquer Estado que garanta a liberdade individual. Ao contrário, a formulação da tese que prioriza o justo sobre o bem determina e exige que "[...] os princípios de justiça sejam justificados por meio de razões

\footnotetext{
${ }^{8}$ Cada pessoa possui uma inviolabilidade fundada na justiça que nem o bem-estar de toda a sociedade pode desconsiderar. Por isso, a justiça nega que a perda da liberdade de alguns se justifique por um bem maior desfrutado por outros. Não permite que os sacrifícios impostos a poucos sejam contrabalançados pelo número maior de vantagens de que desfrutam muitos. Por conseguinte, na sociedade justa as liberdades da cidadania igual são consideradas irrevogáveis; os direitos garantidos pela justiça não estão sujeitos a negociações políticas nem ao cálculo de interesses sociais.
} 
que todos os cidadãos, imersos em eticidades diferentes, poderiam aceitar (ou pelo menos por razões que ninguém poderia razoavelmente rejeitar), independentemente do recurso à coerção". Tal assertiva é ponto comum entre os autores do liberalismo por estruturar a noção de autonomia em detrimento à imposição pelo ente público de concepções de vida que frustrem a escolha pessoal aceitável por cada indivíduo (RAWLS, 2008, p. 13-15) $)^{9}$.

É necessário ter em vista que a justiça como equidade é uma tese de John Rawls que se propõe a pensar um sistema de igualdade e cooperação social, na qual se encontram pessoas livres e iguais entre si. A questão fundamental está em se estabelecer o que é justo e o que é injusto para aquela determinada sociedade. No bojo dessa discussão, Rawls procura retirar toda espécie de particularismo ao expor uma estrutura pública e objetiva. A validação normativa de sua tese moral da justiça como equidade encontra vazão em dois pontos de sustentação. O primeiro deles é o da posição original sob o véu da ignorância e o segundo o do equilíbrio reflexivo. Ambos contribuirão para enunciar os princípios basilares do Estado.

A posição original é considerada um preceito teórico ainda mais abstrato do que a tese dos contratualistas em geral, e comunga do fato de ser uma situação puramente hipotética. Segundo Rawls, esta posição corresponde ao estado de natureza das teorias contratuais tradicionais e dispõe das seguintes características: o fato de ninguém conhecer seu lugar na sociedade, sua classe ou seu status social, e ainda de que ninguém deverá conhecer sua sorte na distribuição dos recursos e das habilidades naturais, sua inteligência, força e coisas do gênero (RAWLS, 2008, p. 13-15).

\footnotetext{
${ }^{9}$ A ideia norteadora é que os princípios de justiça para a estrutura básica da sociedade constituem o objeto do acordo original. São eles os princípios que pessoas livres e racionais, interessadas em promover seus próprios interesses, aceitariam em uma situação inicial de igualdade como definidores das condições fundamentais de sua associação. Esses princípios devem reger todos os acordos subsequentes; especificam os tipos de cooperação social que se podem realizar e as formas de governo que se podem instituir "[...] Devemos imaginar que aqueles que entram em cooperação social escolhem juntos, em um único ato conjunto, os princípios que devem atribuir os direitos e os deveres fundamentais e determinar a divisão dos benefícios sociais." (RAWLS, 2008, p. 13-15).
} 
Essas assertivas constituem para John Rawls o chamado véu da ignorância, ou seja, a inexistência do conhecimento prévio sobre a posição social na escolha dos princípios de justiça. Desta forma, a escolha ocorrida sobre o véu da ignorância extirparia favorecimentos ou conluios na eleição dos princípios, já que ninguém poderia prever o lugar que assumiria na sociedade. A consequência da escolha realizada sob este véu da ignorância é o que permite a Rawls intitular a sua teoria de justiça como equidade, ou seja, há um apelo pela isonomia na constituição dos princípios basilares que inspiram a reconstrução social.

O véu da ignorância é um ponto elementar na teoria como equidade, pois é o que garante a isonomia dos cidadãos, velando para que não prevaleçam peculiaridades que pudessem ensejar em benefício ou malefício de uma classe de cidadãos, como questões de gênero, posição geográfica, doutrinas morais, políticas ou religiosas, entre tantos outros elementos específicos pelos quais se constituem pequenos grupos com identidades semelhantes ${ }^{10}$. A posição original, portanto, é este "artifício de representação" ou "procedimento de justificação" que conjuga os princípios de justiça - razão teórica - às formalidades da razão prática; mais do que isso, "[...] ela formaliza o ponto de vista moral imparcial que possibilita a escolha de princípios para julgar as questões políticas fundamentais." (WERLE, 2015, p. 269).

O segundo ponto de sustentação de sua teoria de justiça como equidade é o equilíbrio reflexivo. Por meio dele se busca a harmonia entre os juízos morais particulares e os princípios de justiça. Nos termos de Silveira (2009, p. 147), o objetivo de Rawls é alçar a teoria da justiça equitativa

\footnotetext{
${ }^{10}$ A esse respeito, Werle $(2015$, p. 267) aduz que “[...] a posição original assegura a imparcialidade e equidade na escolha dos princípios, de modo que sua justificação não dependa de razões éticas particulares, das características e circunstâncias particulares de uma eticidade particular". O véu da ignorância explicita as condições razoáveis que delimitam o espectro de razões e informações moralmente válidas, isto é, que podem fundamentar princípios de justiça numa sociedade marcada pelo pluralismo. Nesse sentido, para justificar a escolha dos princípios, as partes não podem contar com boas razões, seja a sua posição particular na sociedade, seja o fato de professarem uma doutrina religiosa, filosófica ou moral abrangente, ou uma concepção particular do bem. Também têm de ser excluídas informações sobre a raça e o grupo étnico, diferenças de gênero e os diversos talentos naturais.
} 
como sendo o senso de justiça fundamental de modo que os princípios escolhidos na posição original sob o véu da ignorância correspondam aos juízos ponderados por toda a sociedade. Porém, essa concepção representa o ideal, e Rawls sabe que é preciso algum método que dialogue entre os princípios de justiça e os juízos ponderados particulares.

A ideia elementar pode ser trabalhada pelas seguintes assertivas: primeiro, partir de juízos morais concordantes entre todas ou pelo menos a maioria das sociedades democráticas - por exemplo, a tolerância religiosa ou a liberdade de expressão -, identificando sua coerência com os princípios de liberdade e de igualdade. Depois, utilizar os princípios da justiça como niveladores de juízos morais em que haverá discordância, como os critérios para a distribuição de bens perante a sociedade. Por fím, tais juízos terem por base uma teoria moral e política ${ }^{11}$. Assim, o método de equilíbrio reflexivo visa revisar crenças particulares em contraste a crenças invariáveis - ou seja, entre os princípios ponderados que, no caso de Rawls, são os princípios de justiça - de modo a obter a melhor forma de diálogo possível entre tais crenças, aproximando os princípios de justiça do cotidiano de julgamentos morais das pessoas.

Todo este procedimento de justificação da justiça não teria fundamento se Rawls não apresentasse uma concepção substantiva do justo, ou seja, quais seriam os princípios de justiça. Deste modo, o itinerário intelectual de Rawls para a definição da teoria da justiça como equidade passa pela escolha dos princípios basilares da concepção da justiça que devem regular todas as críticas e reformas subsequentes das instituições existentes, ou seja, tais princípios constituem um ponto arquimediano em sua obra. A despeito de se aproximar do contratualismo, o autor não pretende lançar sua teoria na fundação do Estado, mas adaptar uma sociedade já existente. Em razão disto, após a escolha destes princípios que nor-

11 Silveira (2009, p. 148) apresenta uma conclusão elucidativa de que o método de equilíbrio reflexivo “[...] é um processo de justificação de crenças, garantindo a identificação da objetividade dos juízos e princípios morais com base na coerência entre eles, sendo um teste para a validação do senso de justiça compartilhado, estabelecendo-se princípios morais de acordo com uma teoria moral e com as convicções morais refletidas, conformando, além disso, os juízos morais convergentes com base na coerência com os princípios da justiça como equidade". 
teiam a concepção de justiça, a sociedade promulgará uma constituição e uma legislatura em consonância aos princípios acordados inicialmente na posição original de modo a paulatinamente transformar toda a sociedade como um reflexo de tais princípios, obtendo-se mais justiça e igualdade.

Assim, John Rawls sustenta que as pessoas, nesta condição de posição original sob o véu da ignorância, provavelmente escolheriam dois princípios. Em seus precisos termos:

Primeiro: cada pessoa deve ter um direito igual ao sistema mais extenso de iguais liberdades fundamentais que seja compatível com um sistema similar de liberdades para as outras pessoas.

Segundo: as desigualdades sociais e econômicas devem estar dispostas de tal modo que tanto (a) se possa razoavelmente esperar que se estabeleçam em benefício de todos como (b) estejam vinculadas a cargos e posições acessíveis a todos. (RAWLS, 2008, p. 73)

O autor aduz que os princípios são distintos entre si para se adequarem à sociedade que também o é: um sistema social define e garante as liberdades e o segundo especifica e estabelece as desigualdades econômicas e sociais ${ }^{12}$. O primeiro princípio é o que Wayne Morrison (2006, p. 471) qualifica de "precedência operacional", isto é, trata-se de uma forma de assegurar que a liberdade preceda todos os demais princípios em escala de importância. Não é por qualquer outra razão que John Rawls é um pensador liberal. Dessa maneira, ele aponta algumas das espécies de liberdades e demais direitos que estariam incluídos no âmbito do primeiro princípio: liberdade política, de expressão e reunião, de consciência e de pensamento, liberdade individual ou integridade física das pessoas, direito à propriedade pessoal, entre outros (RAWLS, 2008, p. 74).

A primazia da liberdade na sociedade gestada na teoria rawlsiana significa que "[...] a liberdade só pode ser limitada em nome da própria liberdade" (RAWLS, 2008, p. 302-303). Ou seja, o autor afirma que não é legítima a limitação da liberdade de um grupo para melhorar as condi-

\footnotetext{
${ }^{12}$ Rawls publicou a primeira edição de seu livro Teoria da Justiça em 1971, no auge da divisão política do mundo entre o capitalismo e o socialismo. Deste modo, não poderia deixar de reconhecer ambas as parcelas de direitos em sua teoria.
} 
ções sociais de outro grupo ${ }^{13}$. Esse é o sentido de precedência operacional apontada por Morrison. Rawls, no entanto, admite dois vieses: o de que a liberdade de algumas pessoas seja praticamente igual entre si, o que não justifica nenhuma atitude positiva, ou ainda que essas liberdades sejam desiguais, o que pode admitir o incremento da liberdade substancial dos que têm menos, sem restringir a liberdade dos demais.

Embora Rawls admita a especial importância que dispõe o primeiro princípio em sua teoria, o autor aduz com o segundo princípio que a existência de desigualdades econômicas e de autoridade somente poderá ser considerada justa se for recompensadora para todos os membros da sociedade, em especial aos mais desfavorecidos por aquela desigualdade. Trata-se do princípio da diferença, no qual o autor reconhece a distinção como um direito desde que haja igualdade no acesso às oportunidades. Ou seja, é bastante normal a existência de diferenças na distribuição de renda e de riquezas e na estruturação de organizações que dispõem, cada uma a seu modo, de diferenças de autoridade e responsabilidade. Enquanto os cargos de autoridade devem ser acessíveis a todos os membros da comunidade, Rawls comenta que não existe a necessidade da distribuição de riqueza ser perfeitamente igual entre os cidadãos, desde que seja vantajoso a todos. Esse princípio deve estar em sintonia tanto com as liberdades fundamentais como com a igualdade de oportunidades (RAWLS, 2008, p. 75).

O critério de justiça para Rawls, a partir dessa relação entre os princípios, seria a sua distribuição uniforme na sociedade, a não ser que qualquer desigualdade seja mais vantajosa. Nesse sentido, a "[...] injustiça se constitui, então, simplesmente de desigualdades que não são vantajosas

13 Segundo Rawls (2008, p. 74-75), tratando sobre os dois princípios de justiça como equidade, “[...] esses princípios devem ser dispostos em uma ordem serial, o primeiro sendo prioritário do segundo". Essa ordenação significa que as violações das iguais liberdades fundamentais protegidas pelo primeiro princípio não podem ser justificadas nem compensadas por maiores vantagens sociais e econômicas. Essas liberdades têm um âmbito principal de aplicação, dentro do qual só é possível limitá-las ou comprometêlas quando entram em conflito com outras liberdades fundamentais. Já que podem ser limitadas quando se chocam umas com as outras, nenhuma dessas liberdades é absoluta; porém, qualquer que seja a forma pela qual se ajustam em um sistema único, esse sistema deve ser igual para todos. 
para todos". O parâmetro rawlsiano é conciliar a tensão natural entre liberdade e desigualdade, nos moldes enunciados. Dessa maneira, a título de resumir o exposto, a presunção de John Rawls é a de que todos os que estivessem por trás do véu da ignorância escolheriam estes dois princípios. Primeiro a liberdade, pois, não tendo qualquer conhecimento sobre a sua situação real ou o local que estariam no seio da sociedade, dar-se-ia preferência a ela como um instrumento mais adequado na persecução de seus objetivos e ideias. Em outra análise, uma vez que o véu da ignorância impede qualquer conhecimento prévio e barra todas as formas de articulações predeterminadas, seria escolhido o segundo princípio como uma forma de minimizar os efeitos no caso de se estar em um nível social inferior. Em ambos os casos, restaria, portanto, a solução menos pior no quadro de possibilidades possível dada a cada pessoa.

É possível concluir, portanto, que a aposta de Rawls está no olhar individual e autoprotetor que cada pessoa cultiva dentro de si: sua presunção seria que, sem ser possível o diálogo com outras pessoas, o individualismo prevaleceria para a escolha do fundamento de justiça social, enunciando uma melhor e uma pior hipótese. Sua aposta está no véu da ignorância: tanto o egoísta como o altruísta ou qualquer que seja o traço psicológico daquele que tem o encargo de estabelecer um critério de divisão dos recursos serão convencidos a lhe repartir em pedaços semelhantes se não possuírem nenhum tipo de conhecimento prévio acerca de qual fatia caberá a cada um.

A justiça como equidade se fundaria em um procedimento racional para a tomada de decisões coletivas, de modo que a sociedade seria erigida com o paulatino combate das intrínsecas desigualdades que a permeiam. Consoante mencionado, o intento de Rawls com a sua teoria da justiça não está na fundação de uma sociedade, em harmonia ao programa contratualista clássico, mas reformular as sociedades democráticas já existentes. E isso se daria pela decantação das instituições aos princípios de justiça escolhidos pelos membros da comunidade: o critério de justiça seria encontrado na maior ou na mais perfeita proximidade com tais princípios, devendo-se repensar as organizações fundadas em opções distintas às eleitas pela sociedade. 


\section{A Crítica de Amartya Sen à Concepção de Justiça de John Rawls}

Álvaro de Vita (1999, p. 472-473) lembra que a indagação basilar que subjaz o pensamento igualitário é "[...] se temos convicções igualitárias, em que aspectos ou com respeito a que deveríamos ter por objetivo tornar as pessoas tão iguais quanto possível?" Assim, analisadas as teorias de justiça de Amartya Sen e John Rawls, é possível claramente verificar suas divergências. Ainda que seus objetivos sejam os mesmos, ou seja, transformar a sociedade em um locus mais justo e igual, os caminhos conceituais adotados pelos autores são distintos: Rawls projeta princípios filosóficos para a mudança social, enquanto Sen se volta para as causas reais de injustiça e desigualdade. A crítica de Amartya Sen à teoria rawlsiana pode ser resumida da seguinte forma: "[...] a caracterização de instituições perfeitamente justas transformou-se no exercício central das teorias da justiça" (SEN, 2011, p. 38).

É oportuno lembrar que a abordagem contratual foi iniciada por Thomas Hobbes e levada adiante por John Locke, Jean-Jacques Rousseau e Imannuel Kant. Já no século XX, essa tradição foi retomada por John Rawls, dadas as particularidades que o autor assumiu do contratualismo ${ }^{14}$. De modo geral, Sen identifica estes autores a partir de seus esforços para construir arranjos institucionais justos para uma sociedade. Os autores contratuais traçavam suas teorias sociais a partir da acepção do pacto social. Nesse sentido, o acordo manifestado no contrato marcaria a transição entre o homem ligado às características da natureza e o homem social emancipado, substituição ocorrida pelo intercâmbio de direitos: a outorga de direitos naturais visando receber algum outro tipo de benefício a partir da vida em comunidade. Amartya Sen denomina esta abordagem de institucionalismo transcendental. Assim como ocorre com os autores contratuais, Sen denomina de transcendentais todas as abordagens que se focam na construção de instituições que permitirão a justiça, sem procurar sanar as desigualdades e injustiça da população - é possível incluir, neste gru-

\footnotetext{
${ }^{14}$ Rawls não assume toda a noção geral da teoria contratual, sobretudo, porque os autores desta corrente divergem entre si em muitos aspectos. Esse tema foi discutido no ponto intitulado A teoria da Justiça como equidade de John Rawls.
} 
po, inclusive, as três correntes citadas anteriormente, ou seja, libertarismo pragmático, igualitarismo econômico e utilitarismo.

O economista identifica dois atributos comuns entre os autores desta corrente de pensamento. O primeiro deles é o de não vincularem o foco de sua análise dentro da categoria de justo e injusto, mas, ao invés disso, concentrarem-se na busca pela justiça perfeita. Em seu ponto de vista, Sen alega que a limitação deste olhar está na busca pela natureza do justo, sem encontrar critérios para buscar alternativas menos injustas que outras. Assim, nenhuma sociedade poderá ser viável. O segundo atributo, que já foi comentado antes, é o de que o institucionalismo transcendental concentra a sua busca na construção de instituições que promoverão a justiça, como o Estado e sua estrutura institucional. O economista lembra, todavia, que tais instituições não possuem vida própria, mas seu funcionamento depende de pessoas que estão em intensa e constante interação. Analisar as instituições sem voltar o seu olhar para as pessoas é no mínimo descartar parte considerável do campo investigativo dos quais emanam os fenômenos sociais. O resultado disto, nos termos de Amartya, "[...] foi o desenvolvimento de teorias da justiça que enfocavam a identificação transcendental das instituições ideais." (SEN, 2011, p. 36).

O fato de criticar tal concepção doutrinária não significa que Amartya Sen não seja capaz de reconhecer sua importância e a profundidade de suas análises ${ }^{15}$. Assim, sobre o institucionalismo transcendental na teoria da justiça como equidade, de John Rawls, o autor comenta a importância deste ponto de vista:

\footnotetext{
${ }^{15}$ Amartya destaca sete pontos importantes da teoria de John Rawls: a ideia de que a equidade é fundamental para a justiça; a concepção de objetividade na razão prática baseada na concepção de razão pública; a concepção de pessoas morais dotadas de senso de justiça e uma concepção do bem; a importância das liberdades básicas, que adquirem destaque na obra de Rawls; a defesa enfática da igualdade de oportunidades a todos; o enfoque voltado às dificuldades das pessoas em situação desfavorecida (políticas públicas de redução da pobreza a partir da privação dos bens primários); e a concepção dos bens primários, na qual “[...] Rawls reconhece indiretamente a importância da liberdade humana em dar às pessoas oportunidades reais [...] para fazerem o que bem entendam com suas próprias vidas." (SEN, 2011, p. 93-95).
} 
É importante observar que, na busca de instituições perfeitamente justas, os institucionalistas transcendentais às vezes também apresentaram análises profundamente esclarecedoras dos imperativos morais e políticos para o comportamento socialmente apropriado. Isso se aplica em especial a Immanuel Kant e John Rawls: ambos participaram de investigações institucionais transcendentais, mas também forneceram análises abrangentes dos requisitos das normas comportamentais. Ainda que eles tenham focado as escolhas institucionais, suas análises podem ser vistas, de forma mais ampla, como abordagens da justiça focadas em arranjos, em que arranjo se refere tanto ao comportamento certo como às instituições certas. (SEN, 2011, p. 93-95)

Entretanto, na sequência do argumento estabelece uma crítica à justiça focada em arranjos, e não em realizações:

É claro que existe um contraste radical entre uma concepção de justiça focada em arranjos e uma concepção focada em realizações: esta necessita, por exemplo, concentrar-se no comportamento real das pessoas, em vez de supor que todas sigam o comportamento ideal. (SEN, 2011, p. 36-37)

No entanto, o economista não exime John Rawls de uma análise pormenorizada de sua teoria da justiça como equidade. Conforme tratado anteriormente, Rawls estabelece uma situação hipotética na qual as pessoas ou seus representantes, na posição original - situação de igualdade primordial - sob o véu da ignorância, elegeriam dois princípios que serviriam como sustentáculo das análises de justiça na sociedade. $\mathrm{O}$ primeiro e mais importante é o que proclama que todos têm igual direito às liberdades fundamentais. O segundo princípio, relacionado ao tratamento desigual dos cidadãos no que tange aos aspectos sociais e econômicos, aduz para as regras de que tais desigualdades devem beneficiar a todos, com exceção de cargos e posições, em que não se admite tratamento desigual em favor de apenas alguns. Sob a ótica de Amartya, fica claro notar que o arcabouço pensado por Rawls é perfeitamente ajustado ao institucionalismo transcendental, pois tem como objetivo identificar regras e institui- 
ções perfeitamente justas sem necessariamente identificar as atuais mazelas sociais no intuito de lhes combater.

Especificamente sobre a teoria rawlsiana, Amartya Sen hesita sobre o acordo que enunciaria os princípios de justiça. E se não houvesse acordo arrazoado, ainda que sob condições de imparcialidade? Na hipótese de escolha de princípios distintos aos apontados por Rawls, estar-se-ia fugindo à "incerteza planejada" do véu que aponta para princípios enunciados de antemão. Na verdade, toda a sistemática de Rawls parte da presunção dos mesmos princípios de justiça: Sen (2001, p. 233 e 235) comenta que “[...] se houvesse princípios concorrentes com diferentes exigências institucionais que emergissem todas pluralmente da posição original, então a história rawlsiana não poderia ser contada da forma que ele a conta”. Em termos reais, a exigência da escolha pelos dois princípios é bastante reduzida para não se dizer irrealizável.

Oportuno lembrar também que Rawls não admite nada menos que unanimidade na escolha dos princípios e, nos termos de Amartya, “[...] a escolha unânime desses princípios de justiça faz boa parte do trabalho no sistema rawlsiano" (SEN, 2011, p. 86). Ainda, o autor arquiteta sua teoria em inúmeras presunções, e o acordo sobre os princípios é uma delas. Sen denomina esta dúvida de problema da factibilidade de encontrar uma solução transcendental acordada.

Nas palavras de Amartya Sen (2011, p. 41):

Os dois princípios de justiça na investigação clássica da 'justiça como equidade' de John Rawls [...] versam em detalhe sobre instituições perfeitamente justas em um mundo no qual todas as alternativas estão disponíveis. Contudo, o que não sabemos é se a pluralidade de razões a favor da justiça permitiria que um conjunto único de princípios de justiça emergisse na posição original. A elaborada exploração da justiça social rawlsiana, que procede passo a passo a partir da identificação e do estabelecimento das instituições justas, estaria emperrada na própria base.

A segunda ordem de problemas na teoria de Rawls apontada por Amartya Sen se vincula sobre a expectativa da solução perfeitamente jus- 
ta: o exercício da razão prática que envolve escolhas reais demandam estruturas para comparar a justiça na escolha entre alternativas que sejam de fato viáveis do ponto de vista prático. Sen (2011, p. 38-40) critica a noção de identificação imparcial de uma situação única perfeita: para ele, esta é a redundância de todas as teorias transcendentais. Factibilidade e redundância são as principais críticas que Amartya desfere contra as teorias transcendentais, dentre elas, a justiça como equidade de John Rawls.

Ademais, outra ordem de críticas enunciadas por Amartya em face da teoria de Rawls se concentra no princípio da diferença - isto é, o segundo princípio - e sua concentração inteiramente em bens primários ${ }^{16}$ para julgar as questões de distribuição. Segundo Sen (2011, p. 296-297), "[...] compreender a natureza e as fontes de privação de capacidades e da iniqüidade é de fato central para eliminar as injustiças manifestas que podem ser identificadas pela argumentação pública". No caso, o economista critica o filósofo pela opacidade de sua teoria em lidar com casos que fogem à normalidade: ao procurar satisfazer as necessidades imanentes da comunidade tendo por base um raciocínio que congrega apenas a satisfação dos bens primários, Rawls negligencia o fato de que a realidade, determinada por fatores variantes, é bem mais complexa que a teoria. Ainda nas palavras de Amartya, "[...] a teoria da justiça, assim como formulada no âmbito do institucionalismo transcendental hoje dominante, transforma muitas das questões mais relevantes da justiça em retórica vazia" (SEN, 2011, p. 56). Deslocar o centro da análise da renda para os bens primários é um artifício, assim como analisar pobreza sobre a égide da renda também constitui um artifício: Sen (2013, p. 20) comenta que "[...] o que de minha parte defendo é preciso olhar para a liberdade efetiva das pessoas de realizarem seus próprios projetos ${ }^{17}$ ".

\footnotetext{
${ }^{16}$ Segundo entendimento de Rawls, os bens primários são bens que as pessoas desejariam ter mais a ter menos. Em Teoria da Justiça, o autor aponta direitos, liberdades e oportunidades, assim como renda e riqueza e as bases sociais do autorrespeito como bens primários (RAWLS, 2008, p. 536).

${ }^{17}$ Nas palavras de Amartya: “[...] uma pessoa pode ter bons meios, mas tais meios serão ineficazes se tal pessoa é afetada por doenças hereditárias ou doenças adquiridas em epidemias ou se ela tem problemas particulares de algum tipo, como alguma incapacidade; cabe notar que, de acordo com as estatísticas do Banco Mundial, por volta de uma a cada seis pessoas no mundo apresenta incapacidades sérias de um tipo ou de outro. Pode-se
} 
A esse respeito, Wayne Morrison (2006, p. 472-473) igualmente desfere críticas a este ponto da justiça como equidade. Segundo ele, a analogia da divisão do bolo é paupérrima para retratar a sociedade, pois parte de uma situação completamente estática: há apenas um bolo, com tamanho fixo e número determinado de pessoas. Logo, a distribuição de justiça em uma sociedade com desigualdades profundas é tarefa muito mais ampla e pormenorizada, sendo necessário vencer resistências de todas as ordens possíveis - tradicionais, culturais, econômicas, entre outras. Assim como Amartya Sen, Morrison lembra que a teoria rawlsiana se apega a um aspecto muito frágil da igualdade, abordando apenas os chamados bens primários. Entretanto, na prática, por exemplo, decisões que envolvam orçamentos públicos com poucos recursos e pressões financeiras internacionais precisam ir muito além de noções simples como renda e riqueza. No fundo, acerca da ideia de que todos em colaboração alcançariam um crescimento razoável, sempre observados os princípios de justiça, Wayne Morrison (2006) comenta que nenhuma pessoa sensata vai arriscar sua liberdade em nome de uma prosperidade da qual só os outros possam desfrutar.

Em contraste ao institucionalismo transcendental, Sen observa que outros autores - como Adam Smith, John Stuart Mill, Karl Marx e Max Weber - produziram diversas abordagens tendo como enfoque as realizações, técnica que o economista indiano considera que se adéqua melhor para um estudo mais abrangente da justiça. A abordagem desses autores, a qual se inclui, foi denominada por Sen como comparativa. O ponto levantado por Amartya Sen é que, a despeito destes autores entre si estabelecerem abordagens bastante distintas, o fato é de que partiram de sociedades reais, com seus erros e acertos, e buscaram teorizar não olvidando deste referencial. Em outras palavras, buscaram algumas soluções para o mundo à sua volta a despeito de lançarem na busca de uma sociedade perfei-

dizer, assim, que há grandes obstáculos à transformação de bens primários em uma vida boa e livre. Por conseguinte, a questão deve ser abordada de uma perspectiva mais ampla e, para tanto, é preciso examinar as liberdades efetivas das pessoas, e não apenas os meios que elas têm, como os bens primários ou a renda, mas é preciso focar-se em suas liberdades formais e no modo como tais liberdades podem acentuar a liberdade de fato." (SEN, 2013, p. 21). 
tamente justa (SEN, 2011, p. 37-38). A diferença destas duas abordagens se dá no modo de construção das indagações que orientam a pesquisa. Por exemplo, os institucionalistas indagariam o que seriam instituições justas, enquanto os outros questionariam os meios pelos quais se poderia promover a justiça. A partir dessa ilustração, a distância conceitual das abordagens e, sobretudo, dos resultados se mostra bastante perceptível.

A par dessas considerações, Rawls enquadra-se no cerne da questão transcendental que Amartya considera insuficiente para estruturar uma teoria da justiça. Nas palavras de Sen (2011, p. 45-46):

O problema com a abordagem transcendental não surge apenas da possível pluralidade de princípios concorrentes que reivindicam relevância para a avaliação da justiça. Dada a importância do problema da não existência de um arranjo social identificável como perfeitamente justo, um argumento extremamente importante a favor da abordagem comparativa da razão prática na justiça não é apenas a inviabilidade da teoria transcendental, mas sua redundância. Se uma teoria da justiça deve orientar a escolha arrazoada de políticas, estratégias ou instituições, então a identificação dos arranjos sociais inteiramente justos não é necessária nem suficiente.

Assim, é bastante clara a crítica de Amartya com relação à dinâmica da teoria que ele denominou transcendental. Como uma forma de síntese do que foi trabalhado, Amartya Sen busca enfocar as realizações em sua teoria da justiça. Ele reconhece a necessidade de estatuir uma teoria para que se estabeleça uma abordagem racional sobre determinado assunto, além de reforçar que não pretende trabalhar com princípios e enunciados no afã de construir regras e instituições justas vislumbrando uma sociedade idílica objetivo da abordagem da justiça contratual, focada em arranjos. Antes disso, pretende olhar para o mundo a sua volta de modo enfrentar as questões relacionadas a "melhoria da justiça e a remoção da injustiça" - abordagem comparativa -, cujo enfoque se assenta nas realizações. 


\section{Conclusão}

O pensamento de Amartya Sen está alinhado com os desafios postos para este novo século. Mais do que busca por cientificidade ou epistemologia, o constitucionalismo democrático erigido com o passar do século XX trouxe à tona a necessidade de se apresentar soluções a problemas específicos. Na luta por direitos, Sen estabelece linhas de ação e critica a tentativa teórico-transcendental de Rawls de reestabelecer uma teoria contratual no afã de legitimar seus princípios de justiça.

Fica claro que a teoria de Amartya Sen tem como enfoque as realizações ao invés das instituições e regras, além de utilizar a abordagem comparativa em detrimento à transcendental. No Estado de Direito, as instituições são importantes e estruturais para qualquer contexto - seja local, regional, nacional ou internacional. No entanto, o foco das realizações defendido por Amartya Sen vai além do quadro organizacional, pretendendo olhar para as vidas dos cidadãos. Esse é o contexto sobre o qual o autor desenvolve profícua pesquisa sobre a liberdade em relação à noção de desenvolvimento, que lhe garantiu o prêmio Nobel de Economia em 1998.

A abordagem da justiça no pensamento de Amartya Sen, portanto, é aquela na qual se visa garantir certa igualdade de oportunidades aos membros de uma sociedade e qualquer noção desenvolvimentista deve passar, antes, pela maior realização possível das liberdades instrumentais. Essa cristalina distância entre Rawls e Sen, no entanto, evidencia apenas dois meios distintos de se analisar questões semelhantes, quais sejam, o modo de se fazer justiça no Estado contemporâneo.

Sem dúvida, a fronteira entre o justo e o injusto tem sido ponto de indagação por todos os que se propõem pensar a vida em coletividade. Nessa toada, esses autores buscam contribuir, cada um a sua distinta maneira, para com os desafios assumidos no Estado democrático de Direito do século XXI, na certeza de que o tema da justiça não cessará de produzir indagações. 


\section{Referências}

MORRISON, Wayne. Filosofia do Direito: dos Gregos ao PósModernismo. São Paulo: Martins Fontes, 2006.

NUNES, Antonio José Avelãs. Introdução à História da Ciência

Econômica e do Pensamento Econômico. Coimbra: Universidade de Coimbra, 2007.

RAWLS, John. Conferência sobre a História da Filosofia Política. São Paulo: Martins Fontes, 2012.

. Uma Teoria da Justiça. 3. ed. São Paulo: Martins Fontes, 2008.

SEN, Amartya. A Ideia de Justiça. São Paulo: Companhia das Letras, 2011.

SEN, Amartya. Desenvolvimento como Liberdade. São Paulo:

Companhia das Letras, 2000.

. Justiça, esperança e pobreza. In: WOLF, Eduardo Org. Pensar a

Filosofia. Porto Alegre: Arquipélago Editorial, 2013. p. 471-496.

. Sobre Ética e Economia. São Paulo: Companhia das Letras,

1999.

SILVEIRA, Denis Coitinho. Posição original e equilíbrio reflexivo em John Rawls: o problema da justificação. Trans/Form/Ação, São Paulo, v. 32, n. 1, p. 139-157, 2009. Disponível em: <http://www2.marilia. unesp.br/revistas/index.php/transformacao/article/view/999>. Acesso em: 26 out. 2016.

VITA, Álvaro de. Justiça distributiva: a crítica de Sen a Rawls. Dados, Rio de Janeiro, v. 42, n. 3, p. 471-496, 1999.

WERLE, Denílson Luis. A ideia de justiça e a prática da democracia. Novos Estudos - CEBRAP, São Paulo, n. 92, p. 153161, mar. 2012. Disponível em: <http://www.scielo.br/pdf/nec/n92/ n92a11.pdf $>$. Acesso em: 26 out. 2016. 
Flávio Pansieri é doutor em Direito pela Universidade Federal de Santa Catarina, mestre em Direito pela Universidade de São Paulo, presidente do Conselho Fundador da Academia Brasileira de Direito Constitucional - ABDConst, professor de Direito Constitucional da Pontifícia Universidade Católica do Paraná (campus de Curitiba) e advogado.

E-mail: pansieri@pansierikozikoski.com.

Endereço profissional: Pontifícia Universidade Católica do Paraná, Rua Imaculada Conceição, n. 1.155, Prado Velho, Curitiba, Paraná - 80215-901. 